\title{
Probiotics: A New Horizon for Treating Childhood Diarrhea in Bangladesh
}

\author{
Md. Abdul Bari, Md. Rabiul Islam* \\ Department of Pharmacy, State University of Bangladesh, Dhaka, Bangladesh \\ Email: ${ }^{\star}$ robi.ayaan@gmail.com
}

How to cite this paper: Bari, Md.A. and Islam, Md.R. (2017) Probiotics: A New Horizon for Treating Childhood Diarrhea in Bangladesh. Food and Nutrition Sciences, 8, 613-623.

https://doi.org/10.4236/fns.2017.86043

Received: April 29, 2017

Accepted: June 18, 2017

Published: June 21, 2017

Copyright $\odot 2017$ by authors and Scientific Research Publishing Inc. This work is licensed under the Creative Commons Attribution International License (CC BY 4.0).

http://creativecommons.org/licenses/by/4.0/

\begin{abstract}
Objectives: Probiotics are microbial cell preparations or living organisms that have a beneficial effect on the health and well being of the host. Probiotics may offer a safe intervention in acute infectious childhood diarrhea to reduce the duration and severity of the illness. In many places, probiotics are overused or misused and often given without professional jurisdiction. The present study was designed to analyze prescription patterns of probiotics in rural area of Bangladesh and to assess the effects of probiotics in proven or presumed infectious childhood diarrhea. Material and Methods: This study was conducted at Manikganj district hospital of Bangladesh from October to December 2016 to accumulate data from 430 respondents. The data were collected by taking prescription details from patients or their relatives by face to face interview with them who were willing to respond. Statistical analysis was performed using statistical software package SPSS, version 23. Results: According to current study oral rehydration therapy was found as a cornerstone for treating pediatric diarrhea. In addition, it was observed that average 3.2 drugs prescribed per encounter and more than $26.4 \%$ prescriptions contained probiotic products. Approximately $35 \%$ probiotics were prescribed by pediatricians. Bacillus and Lactobacillus were found to be the most frequently prescribed probiotic species for treating childhood diarrhea in Bangladesh. Both antibiotics and probiotics were prescribed to one-third of pediatric patients suffering from diarrhea. Only oral solid (63.7\%) and oral liquid (36.3\%) were prescribed as probiotic products for pediatric patients. Conclusion: It is hoped that the outputs of the present study on probiotics will be used as a science-based assessment tool for managerial decisions on probiotics. This study will help to develop the guidelines and a practical model for the industry to scientifically evaluate probiotics in food. As a national priority, it is expected that these outputs will be useful for the government policy makers to evaluate probiotics on health benefits and the study results can also be used as a scientific tool for the assessment of this new therapeutic option.
\end{abstract}




\section{Keywords}

Probiotics, A New Horizon, Childhood Diarrhea, Bangladesh

\section{Introduction}

According to World Health Organization (WHO) diarrhea is defined as three or more watery or loose stools (taking the shape of the pot) in a twenty four hour period. Acute diarrhea is defined as if the illness started fourteen days back and the episode has lasted fourteen days or more [1]. Exclusively breastfed infants may pass loose pale stools frequently without having diarrhea and for this group, the definition is generally based on what the mother considers to be diarrhea [2]. An episode of infectious diarrhea is caused by an infectious agent and it occurs much more frequently in developing countries than developed countries [3]. Diarrhea is considered as the second leading cause of death among children less than 5 years of age worldwide that is caused by bacteria, viruses, parasites, and non-infectious agents [4]. Attack rates of infectious diarrhea in developing countries are normally six to twelve episodes per child per year, compared with two episodes in the USA [5]. Deaths caused by diarrhea are common in developing countries for children younger than five years, and account for 2.4 to 3.3 million deaths per year [6]. In developed countries, deaths caused by diarrhea are mainly in the elderly [5]. Worldwide, diarrhea is caused by many infectious agents but rotavirus is the most common agent for severe diarrhea and diarrhea mortality among young children [7]. Other significant viral pathogens are enteroviruses and adenoviruses. Bacterial pathogens including enterotoxigenic E. coli, Shigella, Yersinia, Salmonella, Vibriocholera and Campylobacter are notable. Cryptosporidium and Giardia are the main parasitic causes of diarrhea. Rotavirus, enterotoxigenic E. coli and Shigella spp. were found the most common isolated pathogens for infectious diarrhea according to an etiological study on young children attending the hospitals in China, India, Mexico, Myanmar, and Pakistan [8] [9]. Acute diarrhea caused by enterotoxigenic E. coli is common among travelers [10] [11]. In practice, most episodes of acute infectious diarrhea are treated without identifying the causative agent. According to local factors such as availability of proper sanitation and pure water, major causes of acute infectious diarrhea will differ. On the contrary with acute infectious diarrhea, there are several factors that contribute to the pathogenesis of persistent diarrhea [12].

There are several objectives for the treatment of acute diarrhea, such as prevent or reverse dehydration, shorten the length of the illness, and reduce the period that a person is infectious. Available pharmacological treatment options are oral rehydration solution, antibiotics, gut motility suppressing agents, and probiotics. The current study only considers the use of probiotics for treating childhood diarrhea. Probiotics have been defined as components of microbial cells or microbial cell preparations that have the beneficial effect on the health and well being of the host [13]. An ancient and widespread practice for beneficial effects 
of probiotics on human health is food fermenting that augments food taste and nutritional value. Lactic acid bacteria and the yeast Saccharomyces are wellknown probiotics [14]. The taxonomy of the lactic acid bacteria relied traditionally on phenotypic characteristics [15]. Food and Agricultural Organization of the United Nations (FAO) and WHO specialist consultation committee emphasized that beneficial effects of one probiotic strain cannot be assumed to similar with other strains [16]. Even very closely related probiotic strains can have different beneficial effects. This implies that reliable identification of probiotic strains is important to get health benefits from it.

The justification for using probiotics in infectious diarrhea is that they act against enteric pathogens by competing for binding sites and available nutrients, making the gut contents acidic, producing a variety of chemicals, and increasing specific and non-specific immune responses [17] [18] [19] [20]. No serious adverse effects of probiotics have been reported by healthy people but infections have been seen in people with impaired immune function [21] [22] [23] [24] [25]. Two systematic reviews of probiotics in acute diarrhea have been published where the effects of all probiotics and of individual strains were analyzed. The study result shows that acute diarrhea lasting three or more days in infants and children can be reduced by 18 hours if the patients get probiotic compared with the placebo group [26]. Probiotics reduced the duration and frequency of diarrhea [27].

The purpose of this current study was to analyze the available therapeutic options for managing childhood diarrhea in Bangladesh. The relevant pharmacological treatments were assessed as well as necessary follow up to prevent future episode were also recommended. To utilize the findings in the relevant field, some good clinical practice for treating childhood infectious diarrhea will be suggested from this study result.

\section{Material and Methods}

A retrospective review of the case notes of inpatients was carried out between October 2016 and December 2016, a total of 430 children with acute diarrhea (duration $<14$ days), age ranging from 6 months to 5 years, were randomly recruited from the inpatient department of Manikganj district hospital, Bangladesh. Patients under the age of 6 months, above the age of 5 years or those having a severe general medical condition were not included in the study. A specialist physician conducted the diagnosis based on the degree of dehydration, physical examination, patient's history, and pathological testing. The data were taken by collection of prescription details from the patients or their relatives by face to face interview with them. The parents or the primary caregivers of the patients were briefed about the purpose of the study and written consent was taken from each of them. Each of the subjects filled up a questionnaire form which contains personal information, socio-economic data, history of illness, family history and other demographic and medical information. As all the patients were very young, the questionnaire forms were filled out with the help of their parents or 
primary caregivers. Study protocol and volunteer consent form was approved by the ethical review committee of Manikganj district hospital. Statistical analysis was performed using the statistical software package SPSS, version 23.0 (SPSS Inc., Chicago, IL). Descriptive data has been given as frequencies and percentages.

\section{Results}

The socio-demographic parameters of the patients have been presented in Table 1. Respondents had a mean age of 36.53 months ( $\mathrm{SD} \pm 8.64)$ and approximately $70 \%$ (301) of patients were found within an age range of $3-36$ months. Among all respondents, 54\% (232) were male and 46\% (198) were female. Roughly $30 \%$ (129) patients were found to be school going children. Approximately $68 \%$ respondents had family income below $25 \mathrm{KBDT}$ (Kilo Bangladeshi Taka) and their mean income was $16.35 \mathrm{KBDT}(\mathrm{SD} \pm 11.26$ ). The average number of drugs prescribed per encounter was 3.2. In $68.7 \%$ (295) prescriptions, the range of drugs prescribed varied from 3 to 4 . There was not a single encounter where no drug was prescribed. Major drug classes prescribed for the treatment of acute childhood diarrhea have shown in Figure 1. Oral rehydration therapy (ORT) was given in almost all the patients where patients were able to take oral medication. For patients having nausea and vomiting along with infectious diarrhea, 5\% dextrose IV injection was prescribed for them. Antibiotics were prescribed in $86.4 \%$ (372) of the prescriptions and these constituted $34.5 \%$ of the total number of prescribed drugs. About 26.4\% (114) patients were prescribed probiotics for the management of infectious diarrhea. Prescribing pattern of probiotics for treating diarrhea has presented in Figure 2. In 30.5\% (131) prescriptions, antibiotics were prescribed in combination with probiotics. Different bacterial strains in prescribed probiotics have been observed to support gut health in childhood infectious diarrhea including Bacillus clausii (34.5\%), Lactobacillus species (32.8\%), Bifidobacterium specifies (23.4\%) and other species (9.3\%).

Table 1. Socio-demographic characteristics of the respondents.

\begin{tabular}{ccccc}
\hline \multirow{2}{*}{ Parameters } & & \multicolumn{2}{c}{ Respondents $(\mathrm{n}=430)$} \\
\cline { 2 - 5 } Age in months & & $\mathrm{n}$ & $\%$ & Mean \pm SD \\
\hline \multirow{2}{*}{ Gender and weight in Kg } & $6-12$ & 122 & 28 & $36.53 \pm 8.64$ \\
& $13-36$ & 112 & 26 & \\
& $37-60$ & 120 & 28 & \\
Monthly family income in KBDT & Male & 232 & 54 & $10.24 \pm 4.73$ \\
& Female & 198 & 46 & $9.36 \pm 3.85$ \\
& Below 10 & 132 & 31 & \\
& $10-25$ & 165 & 38 & $16.35 \pm 11.26$ \\
& $26-40$ & 90 & 21 & \\
& Above 40 & 43 & 10 & \\
\hline
\end{tabular}




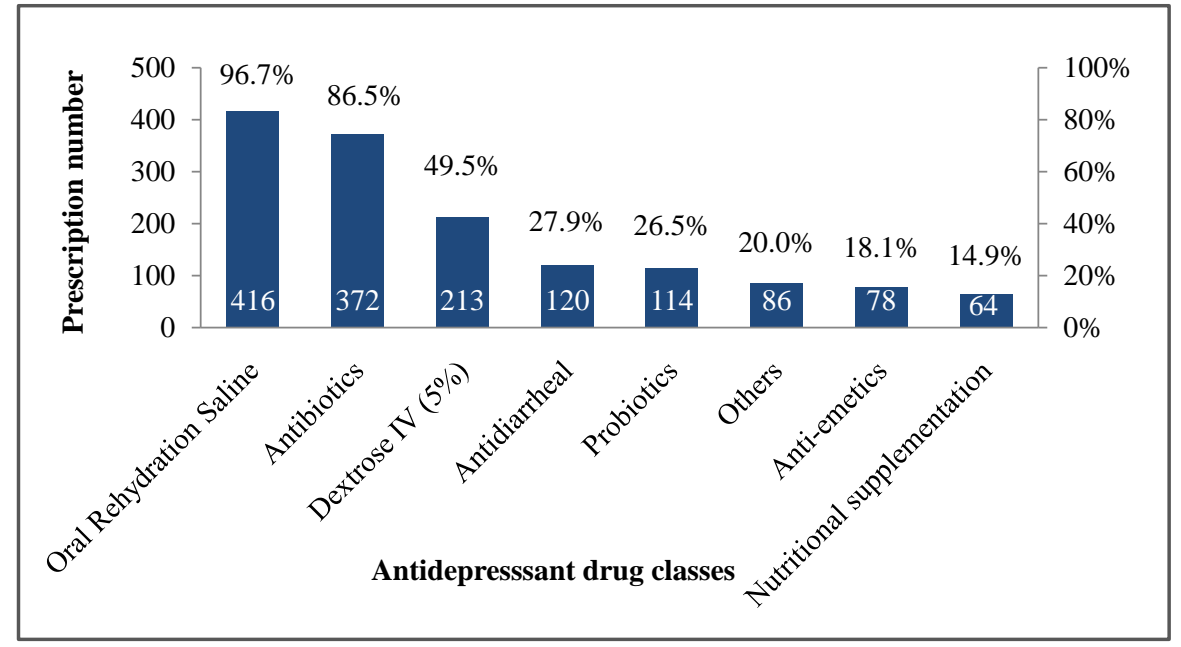

Figure 1. Distribution of medication prescribed for treating childhood diarrhea. Figure shows number and frequency of prescribed drugs with their therapeutic classes.
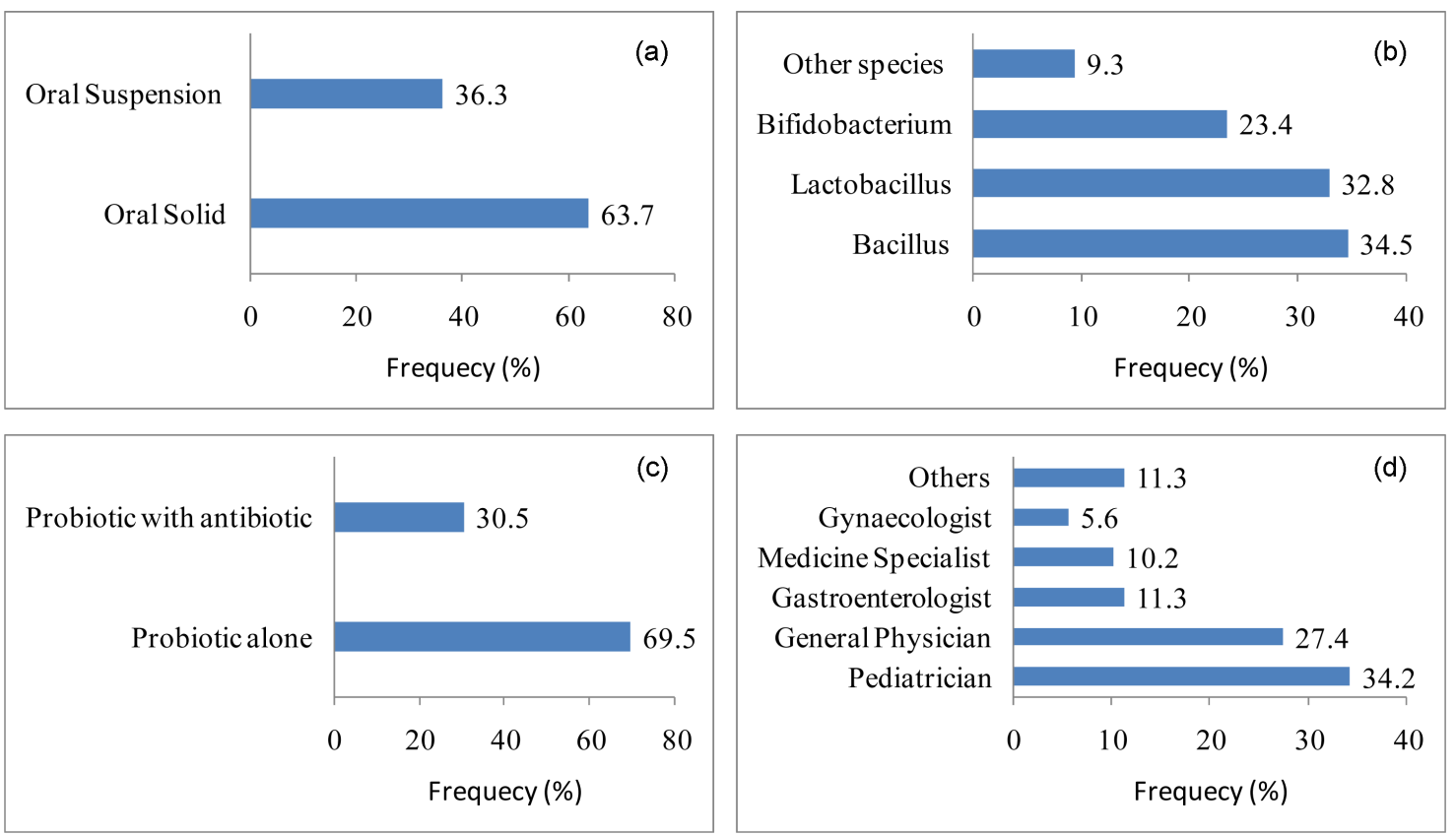

Figure 2. Probiotic prescribing pattern at inpatient department of a district hospital in Bangladesh. The collected data were analyzed based on available probiotic formulation (a), bacterial species (b), prescription with or without antibiotic (c), major prescriber groups (d) in Figure 1.

Among all prescribed probiotics, 36.3\% were oral suspension preparation and $63.7 \%$ were oral solid (sachet or capsule). At hospital level, $34.2 \%$ probiotics were prescribed by pediatricians followed by medical officer, gastroenterologists, medicine specialists, gynecologists and other specialty physicians prescribed $27.4 \%$, $11.3 \%, 10.2 \%, 56 \%$, and $11.3 \%$ of probiotics in different indications, respectively. In most cases, duration of probiotic therapy was observed for 5 - 7 days.

\section{Discussion}

The current study was conducted to explore the anti-diarrheal drug prescribing 
practice at inpatient department of a district hospital in Bangladesh. The main findings of this study were comparable with similar studies in some other countries in Asia. The main findings revealed that children generally attacked by infectious diarrhea within first five years of their life. Similar result was reported in another study e.g. 4.5 episodes per child per year happened in low- and middle-income countries where the incidence rates are highest among infants of 6 11 months of age [28]. Average 3.2 drugs were prescribed per encounter to treat diarrhea which is similar with other study results in low-income countries [29]. Acute infectious diarrhea is still a major cause of childhood morbidity. It is also a source of anxiety to families of affected children and represents a heavy economic burden for families and for society as a whole [30] [31]. As per present study, mainly ORS, antibiotics, anti-emetics and probitics were prescribed for treating acute infectious diarrhea. Similar results were reported in other studies where drugs affect intestinal motility, ion transport and adsorptive moieties, and living bacteria had been prescribed to reduce the duration of diarrhea [30] [31] [32].

In 1975, the United Nations International Children's Emergency Fund (UNICEF) and the World Health Organization (WHO) decided to endorse a single solution (WHO-ORS) containing (in mmol/L): sodium, 90; chloride, 80; potassium, 20; glucose, $111(2 \%)$ and base, 30. This solution was chosen because of the understanding that endorsement of a single solution among populations with all levels of education in different countries would be more practical and simpler than many solutions of various compositions. In reality, clinical studies showed that ORS was found to be similarly effective in treating diarrhea and cholera caused by enterotoxigenic $E$. coli [33]. Studies confirmed the efficacy of ORS for the treatment of infectious childhood diarrhea caused by rotavirus as well [34] [35] [36] [37]. Regardless of patient age, initial serum sodium value, and etiologic agent of diarrhea, the use and acceptance of ORS for treating diarrhea are well recognized [33] [38] [39]. For the successful ORT programs conducted by WHO, death rates caused by diarrhea have reduced significantly [40]. Several clinical studies have reported the efficacy and safety of ORT in developing countries [41] [42]. The result of above initiatives was reflected in this current study where rehydration saline in oral or IV form was prescribed to each and every patient to treat acute diarrhea.

The present study showed that antibiotics were prescribed to $86.4 \%$ pediatric patients where as antimicrobial agents and other drugs have limited usefulness in the management of acute diarrhea. For treating acute diarrhea, antimicrobial therapy varies depending on the causative agent. Though, viral agents are the major causes of acute diarrhea where antimicrobial therapy plays a limited role. The above situation is very much similar with some other research findings in the neighboring country. In India, antibiotics were prescribed to $75 \%$ of pediatric patients for treating diarrhea [43]. However, in certain diarrheal diseases require appropriate antibiotics in addition to nutritional and fluid therapy. Identification of patients who need antimicrobial therapy depends on epidemiologic, clinical, and laboratory support. Vomiting and watery diarrhea in a child less 
than 2 years of age is generally expected to represent viral gastroenteritis and hence do not need antimicrobial therapy. A full discussion of antimicrobial therapy for gastrointestinal tract infections was found in other published reports [44] [45] [46].

Probiotics have progressively gained a significant market share for the treatment of pediatric diarrhea. Current study found $26.4 \%$ patients were prescribed probiotic with other medications for their diarrhea treatment which supported by many study findings in some other countries [47] [48] [49]. Therefore, safety properties and proven efficacy are required for marketing of probiotic products [50]. In addition, the term "probiotic" is not always properly used and the information about specific probiotic products and the strains contained in the products is not comprehensive [51]. In addition to rehydration therapy, probiotics come out as a safe and beneficial option for shortening the duration of diarrhea and reducing stool frequency in acute situation. Still, more research is required to guide the use of particular probiotic regimens for the specific patient groups [52].

The limitation of this study was it did not investigate whether the patients have any special reason for diarrhea which can be solved only by ORS where use of antibiotics and probiotics are redundant. Therefore, further study may be needed to determine whether antibiotics and probiotics are really required to influence on the prescribing habit of anti-diarrheal drugs. Current study didn't cover the qualitative and quantitative investigation of the microbial content of the probiotic preparations in this trial because the objective of this study was to carry out a field trial on commercially available probiotic products prescribed by the psysician. Another drawback of the present study was small number of samples from single center. So, if any study wants to produce more and more valued conclusion then it should be carried out over large number of samples from different regional part of country. In spite of these limitations, I hope this study will play an important role to understand about the current status of probiotics for treating childhood diarrhea in Bangladesh.

\section{Conclusion}

The results of the present study showed that ORS is the corner stone for treating childhood diarrhea in Bangladesh. In many cases, antibiotics are overused or misused and often given without professional justification on for treating diarrhea. Current study observed high rates of antibiotic utilization during the treatment of diarrhea in pediatric patients. These findings suggested for the need of combined interventions using expert counseling and education targeted to the clinical conditions and classes of antibiotic for which inappropriate usage is most common. Use of probiotics for treating childhood diarrhea is increasing and according to these findings, now more than cases thirty percent prescriptions contain probiotics with other anti-diarrheal drugs. It is expected that this investigation will be helpful for treating childhood diarrhea with more perfection in drug assortment and benefit to the patients. 


\section{Acknowledgements}

The authors are thankful to all the staffs of inpatient department of Manikganj district hospital, Bangladesh and the nearby pharmacies for their precious time, technical and administrative support for data collection throughout the study period. The authors are also thankful to all the patients and their caregivers for their cooperation in this study.

\section{Consent to Publish}

All study participants or their primary caregivers acknowledged that anonymous data would be published in journal articles.

\section{Availability of Data and Materials}

Data supporting these findings are contained within the manuscript.

\section{Competing Interests}

The authors declare that they have no competing interests.

\section{References}

[1] Anonymous (1988) Persistent Diarrhoea in Children in Developing Countries: Memorandum from a WHO Meeting. Bulletin of the World Health Organization, 66, 709-717.

[2] WHO (1990) Division of Diarrhoeal and Acute Respiratory Disease Control. The Treatment of Diarrhoea. A Manual for Physicians and Other Senior Health Workers. World Health Organization, Geneva, 20-21.

[3] Guerrant, R.L., Hughes. J.M., Lima, N.L. and Crane, J. (1990) Diarrhea in Developed and Developing Countries: Magnitude, Special Settings, and Etiologies. Reviews of Infectious Diseases, 12, S41-S50. https://doi.org/10.1093/clinids/12.Supplement_1.S41

[4] Ayukekbong, J.A., Mesumbe, H.N., Oyero, O.G., Lindh, M. and Bergström, T. (2015) Role of Noroviruses as Aetiological Agents of Diarrhea in Developing Countries. Journal of General Virology, 96, 1983-1999. https://doi.org/10.1099/vir.0.000194

[5] Savarino, S.J. and Bourgeois, A.L. (1993) Epidemiology of Diarrhoeal Diseases in Developed Countries. Transactions of the Royal Society of Tropical Medicine and Hygiene, 87, 7-11. https://doi.org/10.1016/0035-9203(93)90529-Y

[6] Bern, C. (1992) The Magnitude of the Global Problem of Diarrhoeal Disease: A Ten-Year Update. Bulletin of the World Health Organization, 70, 705-714.

[7] Cunliffe, N.A., Kilgore, P.E., Bresee, J.S., Steele, A.D., Luo, N., Hart, C.A., et al. (1998) Epidemiology of Rotavirus Diarrhoea in Africa: A Review to Assess the Need for Rotavirus Immunization. Bulletin of the World Health Organization, 76, 525 537.

[8] Hodges, K. and Gill, R. (2010) Infectious Diarrhea: Cellular and Molecular Mechanisms. Gut Microbes, 1, 4-21. https://doi.org/10.4161/gmic.1.1.11036

[9] Huilan, S., Zhen, L.G., Mathan, M.M., Mathew, M.M., Olarte, J., Espejo, R., et al. (1991) Etiology of Acute Diarrhoea among Children in Developing Countries: A Multicentre Study in Five Countries. Bulletin of the World Health Organization, 69, 549-555. 
[10] Davoodabadi, A., Soltan Dallal, M.M., Lashani, E. and Tajabadi Ebrahimi, M. (2015) Antimicrobial Activity of Lactobacillus spp. Isolated From Fecal Flora of Healthy Breast-Fed Infants against Diarrheagenic Escherichia coli. Jundishapur Journal of Microbiology, 8, e27852. https://doi.org/10.5812/jjm.27852

[11] Black, R.E. (1986) Pathogens That Cause Traveler's Diarrhea in Latin America and Africa. Reviews of Infectious Diseases, 8, S131-S135. https://doi.org/10.1093/clinids/8.Supplement_2.S131

[12] Walker-Smith, J.A. (1993) Malnutrition and Infection. Transactions of the Royal Society of Tropical Medicine, 87, 13-15. https://doi.org/10.1016/0035-9203(93)90530-4

[13] Salminen, S., Ouwehand, A., Benno, Y. and Lee, Y.K. (1999) Probiotics: How Should They Be Defined? Trends in Food Science and Technology, 10, 107-110. https://doi.org/10.1016/S0924-2244(99)00027-8

[14] Naidu, A.S., Bidlack, W.R. and Clemens, R.A. (1999) Probiotic Spectra of Lactic Acid Bacteria (LAB). Critical Reviews in Food Science and Nutrition, 39, 13-126. https://doi.org/10.1080/10408699991279187

[15] Klein, G., Pack, A., Bonaparte, C. and Reuter, G. (1998) Taxonomy and Physiology of the Probiotic Lactic Acid Bacteria. International Journal of Food Microbiology, 41, 103-125. https://doi.org/10.1016/S0168-1605(98)00049-X

[16] FAO/WHO (2001) Joint FAO/WHO Expert Consultation on Evaluation of Health and Nutritional Properties of Probiotics in Food Including Powder Milk and Live Lactic Acid Bacteria. Food and Agriculture Organization of the United Nations (FAO)/World Health Organization (WHO).

[17] Smith, T.J., Margolis, L.M. and Young, A.J. (2010) Should Military Dining Facilities Offer and Promote Consumption of Probiotic-Containing Foods? Military Medicine, 175, 770-783. https://doi.org/10.7205/MILMED-D-10-00024

[18] Gismondo, M.R., Drago, L. and Lombardi, A. (1999) Review of Probiotics Available to Modify Gastrointestinal Flora. International Journal of Antimicrobial Agents, 12, 287-292.

[19] Goldin, B.R. (1998) Health Benefits of Probiotics. The British Journal of Nutrition, 80, 203-207.

[20] Vanderhoof, J.A. and Young, R.J. (1998) Use of Probiotics in Childhood Gastrointestinal Disorders. Journal of Pediatric Gastroenterology and Nutrition, 27, 323332. https://doi.org/10.1097/00005176-199809000-00011

[21] Hata, D., Yoshida, A., Ohkubo, H., Mochizuki, Y., Hosoki, Y., Tanaka, R., et al. (1988) Meningitis Caused by Bifidobacterium in an Infant. The Pediatric Infectious Disease Journal, 7, 669-671. https://doi.org/10.1097/00006454-198809000-00018

[22] Piarroux, R., Millon, L., Bardonnet, K., Vagner, O. and Koenig, H. (1999) Are Live Saccharomyces Yeasts Harmful to Patients? The Lancet, 353, 1851-1852.

https://doi.org/10.1016/S0140-6736(99)02001-2

[23] Salminen, S., von Wright, A., Morelli, L., Marteau, P., Brassart, D., de Vos, W.M., et al. (1998) Demonstration of Safety of Probiotics-A Review. International Journal of Food Microbiology, 44, 93-106. https://doi.org/10.1016/S0168-1605(98)00128-7

[24] Saxelin, M., Chuang, N.H., Chassy, B., Rautelin, H., Makela, P.H., Salminen, S., et al. (1992) Lactobacilli and Bacteremia in Southern Finland, 1989-1992. Clinical Infectious Diseases, 22, 564-566. https://doi.org/10.1093/clinids/22.3.564

[25] Sussman, J., Baron, E., Goldberg, S., Kaplan, M. and Pizzarello, R. (1986) Clinical Manifestations and Therapy of Lactobacillus Endocarditis: Report of a Case and Review of the Literature. Reviews of Infectious Diseases, 8, 771-776. 
https://doi.org/10.1093/clinids/8.5.771

[26] Szajewska, H. and Mrukowicz, J.Z. (2001) Probiotics in the Treatment and Prevention of Acute Infectious Diarrhoea in Infants and Children: A Systematic Review of Published Randomized, Double-Blind, Placebo-Controlled Trials. Journal of Pediatric Gastroenterology and Nutrition, 33, S17-S25. https://doi.org/10.1097/00005176-200110002-00004

[27] Van Niel, C.W., Feudtner, C., Garrison, M.M. and Christakis, D.A. (2002) Lactobacillus Therapy for Acute Infectious Diarrhoea in Children: A Meta-Analysis. Pediatrics, 109, 678-684. https://doi.org/10.1542/peds.109.4.678

[28] Fischer Walker, C.L., Perin, J., Aryee, M.J., Boschi-Pinto, C. and Black, R.E. (2012). Diarrhea Incidence in Low- and Middle-Income Countries in 1990 and 2010: A Systematic Review. BMC Public Health, 12, 220. https://doi.org/10.1186/1471-2458-12-220

[29] Diallo, A.F., Cong, X., Henderson, W.A. and McGrath, J. (2017) Management of Childhood Diarrhea by Healthcare Professionals in Low Income Countries: An Integrative Review. International Journal of Nursing Studies, 66, 82-92. https://doi.org/10.1016/j.ijnurstu.2016.08.014

[30] Guandalini, S. (2000) Treatment of Acute Diarrhea in the New Millennium. Journal of Pediatric Gastroenterology and Nutrition, 30, 486-489. https://doi.org/10.1097/00005176-200005000-00004

[31] Zimmerman, C.M., Bresee, J.S., Parashar, U.D., Riggs, T.L., Holman, R.C. and Glass, R.I. (2001) Cost of Diarrhea-Associated Hospitalizations and Outpatient Visits in an Insured Population of Young Children in the United States. The Pediatric Infectious Disease Journal, 20, 14-19. https://doi.org/10.1097/00006454-200101000-00004

[32] Farthing, M.J.G. (2000) Novel Targets for the Pharmacotherapy of Diarrhoea: A View for the Millennium. Journal of Gastroenterology and Hepatology, 15, G38G45. https://doi.org/10.1046/j.1440-1746.2000.02264.x

[33] Hirschhorn, N. (1990) The Treatment of Acute Diarrhea in Children: An Historical and Physiological Perspective. The American Journal of Clinical Nutrition, 33, 637663.

[34] Thiagarajah, J.R., Ko, E.-A., Tradtrantip, L., Donowitz, M. and Verkman, A.S. (2014) Discovery and Development of Antisecretory Drugs for Treating Diarrheal Diseases. Clinical Gastroenterology and Hepatology, 12, 204-209. https://doi.org/10.1016/j.cgh.2013.12.001

[35] Molla, A.M., Rahaman, M., Sarker, S.A., et al. (1981) Stool Electrolyte Content and Purging Rates in Diarrhea Caused by Rotavirus, Enterotoxigenic E. coli and V. cholerae in Children. The Journal of Pediatrics, 98, 835-838. https://doi.org/10.1016/S0022-3476(81)80863-3

[36] Nalin, D.R., Levine, M.M., Mata, L., et al. (1979) Oral Rehydration and Maintenance of Children with Rotavirus and Bacterial Diarrheas. Bulletin of the World Health Organization, 57, 453-459.

[37] Sack, D.A., Rhoads, M., Molla, A., et al. (1982) Carbohydrate Malabsorption in Infants with Rotavirus Diarrhea. The American Journal of Clinical Nutrition, 36, 1112-1118.

[38] Pierce, N.F. and Hirschhorn, N. (1977) Oral Fluid Is a Simple Weapon against Dehydration: How It Works and How to Use It. WHO Chronicle, 31, 87-93.

[39] Pizarro, D., Posada, G., Villavicencio, N., et al. (1983) Oral Rehydration in Hypernatremic and Hyponatremic Diarrheal Dehydration: Treatment with Oral Glucose/ Electrolyte Solution. American Journal of Diseases of Children, 137, 730-734. 
https://doi.org/10.1001/archpedi.1983.02140340014003

[40] WHO (1984) World Health Organization, Diarrheal Diseases Control Programme. Impact of Routine Use of ORT in Hospitals in 19 Countries. WHO, The Weekly Epidemiological Record, 63, 49-52.

[41] Freedman, S.B., Ali, S., Oleszczuk, M., Gouin, S. and Hartling, L. (2013) Treatment of Acute Gastroenteritis in Children: An Overview of Systematic Reviews of Interventions Commonly Used in Developed Countries. Evidence-Based Child Health, 8, 1123-1137. https://doi.org/10.1002/ebch.1932

[42] Snyder, J.D. (1991) Use and Misuse of Oral Therapy for Diarrhea: Comparison of U.S. Practices with American Academy of Pediatrics Recommendations. Pediatrics, 87, 28-33.

[43] Ahmad, A., Khan, M.U., Malik, S., Mohanta, G.P., Parimalakrishnan, S., Patel, I. and Dhingra, S. (2016). Prescription Patterns and Appropriateness of Antibiotics in the Management of Cough/Cold and Diarrhea in a Rural Tertiary Care Teaching Hospital. Journal of Pharmacy \& Bioallied Sciences, 8, 335-340. https://doi.org/10.4103/0975-7406.199340

[44] Pickering, L.K. (1991) Therapy for Acute Infectious Diarrhea in Children. The Journal of Pediatrics, 118, S118-S128. https://doi.org/10.1016/S0022-3476(05)81439-8

[45] AAP (1991) American Academy of Pediatrics, Report of the Committee on Infectious Diseases (Red Book). 22nd Edition.

[46] WHO (1990) The Rational Use of Drugs in the Management of Acute Diarrhea in Children. World Health Organization, Geneva.

[47] Szajewska, H., Setty, M., Mrukowicz, J. and Guandalini, S. (2006) Probiotics in Gastrointestinal Diseases in Children: Hard and Not-So-Hard Evidence of Efficacy. Journal of Pediatric Gastroenterology and Nutrition, 42, 454-475. https://doi.org/10.1097/01.mpg.0000221913.88511.72

[48] Reid, G., Jass, J., Sebulsky, M.T. and McCormick, J.K. (2003) Potential Uses of Probiotics in Clinical Practice. Clinical Microbiology Reviews, 16, 658-672. https://doi.org/10.1128/CMR.16.4.658-672.2003

[49] Szajewska, H., Hoekstra, J.H. and Sandhu, B.; The Working Group on Acute Diarrhoea of the European Society for Paediatric Gastroenterology, Hepatology and Nutrition. (2000) Management of Acute Gastroenteritis in Europe and the Impact of the New Recommendations: A Multicenter Study. Journal of Pediatric Gastroenterology and Nutrition, 30, 522-527. https://doi.org/10.1097/00005176-200005000-00011

[50] Young, J. (1998) European Market Developments in Prebiotic- and Probiotic-Containing Foodstuffs. British Journal of Nutrition, 80, S231-S233.

[51] Drago, L., De Vecchi, E., Nicola, L., Colombo, A. and Gismondo, M.R. (2004) Microbiological Evaluation of Commercial Probiotic Products Available in Italy. Journal of Chemotherapy, 16, 463-467. https://doi.org/10.1179/joc.2004.16.5.436

[52] Allen, S.J., Martinez, E.G., Gregorio, G.V. and Dans, L.F. (2010) Probiotics for Treating Acute Infectious Diarrhoea. The Cochrane Database of Systematic Reviews, 10, CD003048. https://doi.org/10.1002/14651858.cd003048.pub3 
Submit or recommend next manuscript to SCIRP and we will provide best service for you:

Accepting pre-submission inquiries through Email, Facebook, LinkedIn, Twitter, etc. A wide selection of journals (inclusive of 9 subjects, more than 200 journals)

Providing 24-hour high-quality service

User-friendly online submission system

Fair and swift peer-review system

Efficient typesetting and proofreading procedure

Display of the result of downloads and visits, as well as the number of cited articles Maximum dissemination of your research work

Submit your manuscript at: http://papersubmission.scirp.org/

Or contact fns@scirp.org 